\title{
Resettlement experiences of African migrants in Australia and how they affect mental health
}

\author{
Irene Ikafa, Laura Perry
}

\begin{abstract}
Citation
Ikafa I, Perry L (2019)

Resettlement experiences of African migrants in Australia and how they affect mental health. Mental Health Practice. doi: 10.7748/mhp.2019.el394

\section{Peer review}

This article has been subject to external double-blind peer review and has been checked for plagiarism using automated software
\end{abstract}

\section{Correspondence}

iikafa@une.edu.au

Accepted

2 May 2019

\section{Published online}

August 2019

\section{Open access}

This is an open access article distributed under the terms of the Creative Commons Attribution 4.0 International licence (CC BY 4.0) (see https:// creativecommons.org/licenses/ by/4.0/), which permits others to copy and redistribute in any medium or format, remix, transform and build on this work, even commercially, provided appropriate credit is given and any changes made indicated

\begin{abstract}
Background An increasing number of African migrants are resettling in Australia. Resettlement may provide them with many benefits, but stressors associated with the resettlement process may have detrimental effects on their mental health and well-being.
\end{abstract}

Aim To examine the resettlement experiences of involuntary and voluntary African migrants, and to explore their mental health and future aspirations.

Method An exploratory, descriptive survey was used to collect information from II5 participants from sub-Saharan African countries. Analysis of group differences was conducted for gender, employment status and country of origin.

Results Participants reported experiencing good mental health and positive future aspirations; there were no significant differences by gender, employment status or country of origin.

Conclusion Most participants experienced good mental health and positive future aspirations, findings which differ from previous studies. Mental health nurses should continually update their knowledge about the mental health services available for migrants and ensure that all migrants can access these services if needed.

\section{Author details}

Irene lkafa, lecturer in nursing, University of New England, Faculty of Medicine and Health, Armidale, New South Wales, Australia; Laura Perry, associate professor, Murdoch University, Perth, Australia

\section{Keywords}

anxiety, mental health, mental health therapies, post-traumatic stress disorder, psychosocial, stress

\section{Introduction}

This article examines the resettlement experiences of involuntary, or refugee, and voluntary African migrants in Australia. Involuntary migrants are forced to leave their country and cannot return due to significant danger, for example, because of civil war. Voluntary migrants are people who decide to move to other countries to seek better life opportunities (Grinberg and Grinberg 1989, Cassidy 2004). To date, studies conducted on the resettlement experiences of African migrants in Australia have focused on involuntary migrants.

The two groups of African migrants, involuntary and voluntary, have commonalities linked to culture and geographical distance from where they previously lived, as well as culture shock, isolation, homesickness, racism, employment issues and financial constraints (Berry 1997, Ward 2000, Abur and Spaaij 2016, Abur 2018), which can have detrimental effects on mental health. However, healthcare professionals find these factors difficult to detect (Ward 2000).
Involuntary migrants may experience added issues due to trauma resulting from civil war, persecution, rape, loss of family or sudden separation from family members who could still be living in danger. Baird (2012) affirmed that many refugee women from South Sudan resettled in the US were separated from their husbands and older sons, who were left behind to fight in a civil war. Often these women would later become widowed. Involuntary migrants may also experience language barriers, loneliness, unemployment and underemployment (Beiser and Hou 2001, Porter and Haslam 2005). Savic et al (2013) reported that separation from family members can create sadness, worry and ongoing stress. For involuntary migrants, post-migration may be followed by grief, guilt, homesickness and resentment that can last for many years after resettlement in a host country (Lustig et al 2004).

The number of African migrants in Australia has increased rapidly over the past two decades: the Australian Bureau of Statistics 
(ABS) census data indicate that the number of people born in Africa rose from about 250,000 in 2006 to 338,000 in 2011, representing an increase of $35 \%$ during this five-year period (ABS 2006, 2011). Previous studies have established a high risk of mental illness among involuntary African migrants (Schweitzer et al 2006, Murray et al 2010).

\section{Literature review}

The process of migration can involve a person or a family moving to seek a better life in another country. This movement of people is not recent; people have been constantly migrating within and to other countries throughout human history (Ingleby 2005). However, the number of migrants worldwide is increasing: the total number of international migrants, for example, increased from an estimated 154 million in 1990 to 175 million in 2000 and to 232 million in 2014 (International Organization for Migration 2015). In 2015, the total number of migrants worldwide was approximately 244 million (United Nations 2015).

The effect of migration is evident throughout historical and recent literature (Ward 2000, Hack-Polay 2012). Ward (2000) found that migration is related to multiple losses and homesickness, which results in some migrants thinking constantly about their homeland, sleeping badly, refusing to eat food and experiencing physical weakness and anxiety. Hack-Polay (2012) identified homesickness among migrant workers and expatriates. HackPolay and Mendy (2018) also found that, regardless of qualifications, migrants were not used in the host's labour market and as a result were rejected and excluded from participative integration. Mendy and Hack-Polay (2018) revealed too that African businesses in Western countries performed badly because society undermined them socially, culturally and economically, which may have affected migrants' mental health.

\section{Resettlement experiences}

Migrating to a new country and culture tends to result in several issues: cultural shock, cultural bereavement, homesickness and loss of social networks (Winkelman 1994, Bhugra and Becker 2005). Ward (2000) purported that migrants may also feel lost, protest and lament their lost homeland, and face uncertainty about their future.

The literature highlights that the worst outcomes in the resettlement of involuntary migrants are associated with post-migration experiences, such as learning to navigate a new society, language and culture, while coping with the loss of their homeland, family and friends (Murray 2010, Baird 2012). Lindencrona et al (2008) found that refugees, resettled in Sweden, experienced alienation, discrimination and threats of violence from the indigenous population.

To help involuntary migrants meet their health needs and overcome post-migration barriers, alternative models of care delivery have included use, for example in Canada, of a mobile clinic providing accessible, linguistic and culturally competent care (Guruge et al 2010).

\section{Experiences of migrants in Australia}

The resettlement experiences of African migrants in Australia may differ from one state to another. African migrants may experience difficulties when trying to adjust to their host state and can face racism, unemployment, financial constraints, gender and role reversal, which may lead to a breakdown of couples or families and can cause mental health problems (Abur and Spaaij 2016, Abur 2018, Kuyini and Kivunja 2018). Ogunsiji et al (2012) also reported that African women were exposed to risk factors, including under- and unemployment, and being forced to 'start again', which affected their mental health. Specifically, a study by Hancock (2009) in Western Australia (WA) argued that settlement agencies there failed to meet the needs of involuntary African migrants, involving for example cultural differences, trauma and racial discrimination, which can affect mental health.

African migrants with young families can find parenting a challenge because they may have to manage this in a new culture and strict parental control may be inconsistent with parenting in their host country (Poppitt and Frey 2007, McMichael et al 2011, Renzaho and Vignjevic 2011, Brand et al 2014, Abkhezr et al 2018). These issues can have a detrimental effect on the mental health of families, particularly children.

Some involuntary African migrants have been forced to separate from their family members because they have fled civil war. Murray et al (2010) found that Sudanese refugees experienced constant stress due to separation from their family, who often remained in refugee camps and in war zones. Separation from family members can create sadness, worry and ongoing stress (Savic et al 2013). Schweitzer et al (2006) found that pre-migration trauma was linked to higher levels of depression and anxiety among Sudanese refugees.

\section{Key points}

- Involuntary migrants, or refugees, are forced to leave their country and cannot return due to significant danger

- Voluntary migrants are people who decide to move to other countries to seek better life opportunities

- All migrants experience cultural shock, cultural bereavement, homesickness and loss of social networks

- Involuntary migrants may experience added issues due to trauma resulting from civil war, persecution, rape, loss of family or sudden separation from family members who could still be in danger

- The number of migrants is increasing worldwide: in 2015, there were about 244 million 
Previous studies have found a high risk of mental illness among involuntary African migrants, but there is a gap in the literature: these studies did not address issues affecting involuntary and voluntary migrants, and they did not compare migrants' mental health and future aspirations with gender, employment status and migrant status.

\section{Aim}

The aim of this study was to examine the resettlement experiences of involuntary and voluntary African migrants, and to explore their mental health and future aspirations.

\section{Method}

The study used an exploratory descriptive survey research design to examine how African migrants perceive their resettlement experiences in Australia. The survey allowed the authors to collect data from a broad range of participants within the budget constraints of the project.

\section{Sample}

The sample included ethnic African migrants from sub-Saharan African countries living in WA. The sampling methods included convenience and purposive because the study aimed to explore the perceptions of a wide range of African migrants from various countries. People were invited to participate if they were an adult, ethnic African migrant of either gender from a sub-Saharan African country, with citizenship or permanent residence in Australia. Non-ethnic Africans, such as white South Africans, and temporary visa holders were excluded.

\section{Participants}

Participants were recruited using several approaches. Leaflets that described the study were distributed and displayed in public places around the Perth metropolitan area, especially in communities with many African migrants. Participants were also recruited from the first author's social networks, and through the African community association of WA. A total sample of 115 migrants, including 63 males and 52 females, from sub-Saharan African countries was obtained (Table 1).

\section{Data collection}

The quantitative data were collected using a self-report survey questionnaire. The survey questionnaire comprised 35 questions, which included five about mental health and six about future aspirations. The other questions concerned: demographic variables, reasons for migrating, pre-migration strategies, number of children, employment status, coping strategies, general health and support services.

\section{Data analysis}

The data from the survey questionnaires were analysed using descriptive statistics, an independent $t$-test, and one- and two-way analysis of variance (ANOVA). Descriptive statistics were used to analyse demographic data. The independent $t$-test was used to compare the mental health scores of participants from war-affected countries and a one-way ANOVA was used to compare the scores between mental health and employment status (unemployed, employed not in their original field and employed in their original field). The independent $t$-test was also used to assess whether mean scores for participants' future aspirations varied by gender.

\section{Table I. Demographic information} about participants

\begin{tabular}{|c|c|c|}
\hline \multicolumn{2}{|c|}{ Demographic factors } & \multirow{2}{*}{$\begin{array}{c}\text { Responses (\%) } \\
54.0\end{array}$} \\
\hline Gender & Male & \\
\hline & Female & 46.0 \\
\hline \multirow[t]{5}{*}{ Marital status } & Married & 53.5 \\
\hline & Single & 36.6 \\
\hline & Cohabiting & 3.6 \\
\hline & Divorced & 2.8 \\
\hline & Separated & 3.5 \\
\hline \multirow[t]{6}{*}{ Age (years) } & $>18$ & 7.0 \\
\hline & $21-30$ & 38.3 \\
\hline & $31-40$ & 27.0 \\
\hline & $41-50$ & 22.6 \\
\hline & $51-60$ & 0.0 \\
\hline & $>60$ & 5.1 \\
\hline \multirow[t]{3}{*}{$\begin{array}{l}\text { Employment } \\
\text { status }\end{array}$} & $\begin{array}{l}\text { Employed in their } \\
\text { original field }\end{array}$ & 48.0 \\
\hline & $\begin{array}{l}\text { Not employed in } \\
\text { their original field }\end{array}$ & 36.0 \\
\hline & Not employed & 16.0 \\
\hline \multirow[t]{2}{*}{ Citizenship } & Australian & 73.5 \\
\hline & $\begin{array}{l}\text { Other permanent } \\
\text { residence }\end{array}$ & 26.5 \\
\hline
\end{tabular}


A two-way between-groups ANOVA was used to compare scores between participants' future aspirations, gender and employment status.

Approval for the study was obtained from the Murdoch University human research ethics committee, at the Perth campus.

\section{Results}

Most participants in this study $(72 \%)$ were involuntary migrants from countries affected by war; the remaining participants $(28 \%)$ were voluntary migrants from countries unaffected by war. Table 2 shows country of origin.

\section{Mental health}

Participants were asked to respond to five statements about their mental health on a four-point Likert scale (Table 3):

\section{Table 2. Country of origin of participants}

\begin{tabular}{|l|c|c|}
\hline Country & \multicolumn{2}{|c|}{ Participants } \\
\hline Botswana & $n$ & $\%$ \\
\hline Burundi & 1 & 0.9 \\
\hline Democratic Republic of Congo & 4 & 3.5 \\
\hline Eswatini & 7 & 6.1 \\
\hline Ethiopia & 1 & 0.9 \\
\hline Ghana & 5 & 4.3 \\
\hline Kenya & 6 & 5.2 \\
\hline Liberia & 16 & 13.9 \\
\hline Malawi & 8 & 7.0 \\
\hline Mauritius & 1 & 0.9 \\
\hline Nigeria & 1 & 0.9 \\
\hline Sierra Leone & 2 & 1.7 \\
\hline Somalia & 7 & 6.1 \\
\hline South Africa & 13 & 11.3 \\
\hline Sudan & 7 & 6.1 \\
\hline Tanzania & 1 & 0.9 \\
\hline Uganda & 4 & 3.5 \\
\hline Zambia & 23 & 20.0 \\
\hline Zimbabwe & 1 & 0.9 \\
\hline
\end{tabular}

॥ $1=$ not at all.

॥ 2 = some of the time.

॥ $3=$ most of the time.

॥ 4 = all the time.

Most participants reported good mental health. Less than $15 \%$ of participants reported experiencing sadness or being unhappy most of or all of the time and the same proportion reported that they had lost interest in other people and social activities. Less than $10 \%$ expressed negative responses on the other three points.

Statistical tests were conducted to examine whether mental health varied between men and women, and between those from countries not affected by war and those from countries that were. The scores of the mental health responses were added to form a composite score for the mental health of each respondent. Low scores represented good mental health and high scores represented poor mental health. These composite scores were then used in the statistical analyses described as follows.

\section{Type of migrant countries}

An independent $t$-test was used to compare the mental health scores of participants from countries unaffected by war (mean $(M)=13.1270$, standard deviation $(\mathrm{SD})=2.67902)$ and those affected $(\mathrm{M}=12.0192, \mathrm{SD}=3.41560)$. An independent $t$-test score was $t(113)=1.949, P=0.054$ $(0.054>0.05)$. This indicated that there was no significant difference between the mental health of participants from countries unaffected by war and that of participants from countries affected by war.

\section{Employment status scores}

A one-way ANOVA was used to compare the scores between mental health and employment status: unemployed $(\mathrm{M}=13.0667, \mathrm{SD}=2.46306)$, employed not in original field $(\mathrm{M}=13.0294$, $\mathrm{SD}=1.88270)$ and employed in original field $(\mathrm{M}=12.0000, \mathrm{SD}=4.06612)$. The main effect of employment status was not significant and so there was no difference between males and females; F value, (2.92)=1.251, was small and therefore the $P$ value was not significant, $P=0.291$ (0.291>0.05). The results showed that there was no significant difference between mental health and unemployment, employed not in original employment field and employed in original employment field.

\section{Future aspirations}

Participants were asked to respond to six items concerning their future aspirations, which were answered on a four-point Likert scale: 
॥ 1 = strongly disagree.

॥ 2 = disagree.

I) 3 = agree.

॥ 4 = strongly agree.

These scores were added to attain a composite score for feelings of each respondent about the future. The results revealed that most participants in this study experienced positive feelings about their future (Table 4).

Statistical tests were conducted to examine whether future aspirations varied between groups of participants. These scores were again added to achieve a composite score on the aspirations of each respondent about their future. High scores represented positive feelings about the future, and low scores represented negative feelings. These composite scores were then used in the statistical analyses described as follows.

\section{Gender}

An independent $t$-test was used to assess whether mean scores for feelings about the future varied by gender. Women had a mean score of $\mathrm{M}=15.0577(\mathrm{SD}=2.58513)$ and men had a mean score of $\mathrm{M}=14.7937$ ( $\mathrm{SD}=3.14262)$. An independent $t$-test score was $t(113)=485, P=0.628$. The results showed that there was no significant difference between men and women in their future aspirations.

\section{Future aspirations, gender} and employment status scores

A two-way between-groups ANOVA was used to compare the scores between future aspirations, gender and employment status. The main effect of gender about future aspirations was not significant $F(1.89)=0.352$, $P=0.554$. The main effect of employment status future aspirations was also not significant $F$ (2.89) $=0.313, P=0.732$.

\section{Interactions}

There was a significant interaction between gender and employment status $F(2.89)=3.394$, $P=0.038$. Men showed negative feelings about their future aspirations if they were unemployed and positive feelings if they were employed in their original employment field.

\section{Table 3. Mental health responses from participants}

\begin{tabular}{|c|c|c|c|c|c|c|c|c|}
\hline \multirow[t]{2}{*}{ Statement } & \multicolumn{2}{|c|}{ Not at all } & \multicolumn{2}{|c|}{ Some of the time } & \multicolumn{2}{|c|}{ Most of the time } & \multicolumn{2}{|c|}{ All of the time } \\
\hline & $n=115$ & $\%$ & $n=115$ & $\%$ & $n=115$ & $\%$ & $n=115$ & $\%$ \\
\hline 1. I am sad or unhappy & 53 & 46.1 & 46 & 40.0 & 11 & 9.6 & 5 & 4.6 \\
\hline $\begin{array}{l}\text { 2. I have lost interest in others and } \\
\text { social activities }\end{array}$ & 68 & 59.1 & 32 & 27.8 & 11 & 9.6 & 4 & 3.5 \\
\hline 3. I cannot make decisions anymore & 88 & 76.5 & 16 & 13.9 & 7 & 6.1 & 4 & 3.5 \\
\hline 4. I feel as though I am bad or worthless & 82 & 71.3 & 25 & 21.7 & 6 & 5.2 & 2 & 1.7 \\
\hline 5. I feel I am a failure as a person & 86 & 74.8 & 21 & 18.3 & 6 & 5.2 & 2 & 1.7 \\
\hline
\end{tabular}

\section{Table 4. Participants' outlook about the future}

\begin{tabular}{|c|c|c|c|c|c|c|c|c|}
\hline \multirow[t]{2}{*}{ Statement } & \multicolumn{2}{|c|}{$\begin{array}{l}\text { Strongly } \\
\text { disagree }\end{array}$} & \multicolumn{2}{|c|}{ Disagree } & \multicolumn{2}{|c|}{ Agree } & \multicolumn{2}{|c|}{ Strongly agree } \\
\hline & $n=115$ & $\%$ & $n=115$ & $\%$ & $n=115$ & $\%$ & $n=115$ & $\%$ \\
\hline 1. I feel secure and safe & 3 & 2.6 & 2 & 1.7 & 13 & 11.6 & 97 & 84.3 \\
\hline 2. I feel able to make my own choices & 8 & 7.0 & 4 & 3.5 & 4 & 3.5 & 99 & 86.1 \\
\hline 3. I am able to fulfil my dreams and goals & 8 & 7.0 & 1 & 0.9 & 9 & 7.8 & 97 & 84.3 \\
\hline 4. I am optimistic about their future & 8 & 7.0 & 1 & 0.9 & 7 & 6.1 & 99 & 86.1 \\
\hline 5. I will be self-reliant in the future & 11 & 9.6 & 4 & 3.5 & 8 & 7.0 & 92 & 80.0 \\
\hline 6. I feel cut off from other people & 19 & 16.5 & 36 & 31.3 & 36 & 31.3 & 24 & 20.9 \\
\hline
\end{tabular}


Similarly, women showed negative feelings about their future aspirations if they were unemployed or employed in their original field but showed positive feelings about their future if they were employed, but not in their original employment field. In summary, men who were employed in their original employment field felt good or positive about their future, but women did not. Women not employed in their original employment field felt good or positive about their future, but men did not. This is an unusual finding, which may require further discussion and research.

\section{Discussion}

One of the findings of this study is that most participants experienced good mental health, which did not vary by gender, employment status or migrant status, voluntary or involuntary. This finding contradicts previous research about African migrants in Australia. Murray et al (2010) found that Sudanese refugees were at high risk of developing mental illness due to ongoing stress related to separation from families who remained in dangerous situations. Similarly, Savic et al (2013) established that separation from family members can create sadness and constant worry.

The reasons for these contradictory findings are unclear, but it may be due to differences between participants in this study compared to others: this study included involuntary and voluntary migrants. Also, the participants in this study had lived in Australia longer, up to 17 years, and most were Australian citizens. Luthra et al (2014) postulated that migrant resident status and needs can influence resettlement outcomes. The authors' findings suggest that African migrants can experience good mental health after resettlement, even if they are involuntary migrants, but that it may take years to attain.

This study's findings also indicate that there was no link between participants' employment status and mental health. This differs from Ogunsiji et al (2012), who found that African women in Australia were exposed to a range of health-related risk factors, including unemployment and underemployment, and being forced to 'start again', which affected their mental health. As previously stated, this could be because the participants were involuntary and voluntary migrants and had lived in Australia a long time.

Studies of non-migrant populations have shown that people who are underor unemployed typically experience worse mental health than people who are employed in their original field of employment. Murphy and Athanasou (1999) examined 16 longitudinal studies on the effect of unemployment on people's mental health. The results were inconclusive, but the authors suggested that, if emotional distress decreases after re-employment, this indicates that loss of employment aggravates emotional distress.

Similarly, Paul and Moser (2009) found that $34 \%$ of the unemployed people in their study experienced mental health problems, compared to $16 \%$ of employed people. Fryer and Payne (1986) reported that unemployed people experienced higher levels of stress than employed people due to financial constraints. The findings of this study suggest that African migrants may be more resilient to the detrimental effects of under- or nonemployment than non-migrants in Australia.

Pittaway et al (2009) reported that African migrants who possessed good English skills and were employed in professional jobs had high levels of satisfaction about their future in Australia. This study builds on these findings by showing that African migrants generally, not just those who are employed in professions, have high levels of satisfaction about their future aspirations.

While most participants experienced good mental health and positive feelings about their future, some experienced sadness and had lost interest in other people and social activities. It is also worth noting that many participants in this study were involuntary migrants, who may have experienced severe trauma associated with civil war, persecution, rape, loss of or sudden separation from family members who could still be living in danger.

Mental health nurses should acknowledge these issues and incorporate them into early clinical assessments and interventions to detect mental health problems that could hinder the resettlement process. Mental health nurses working with African migrants should undertake mandatory cultural training, which should be reviewed regularly to ensure that culturally competent care is delivered to this cohort of migrants.

\section{Limitations}

This study is limited by its sample; convenience and purposive sampling techniques were used to recruit volunteers in one state so the findings may not be generalisable. Participants who engaged in the study could interpret English; there is a possibility that participants in this study may have self-selected by being able to read recruitment leaflets. Future studies could use a randomised sampling 
strategy and more participants from all states in Australia to provide a more detailed understanding of the issues facing voluntary and involuntary migrants.

\section{Conclusion}

This study explored the resettlement experiences of voluntary and involuntary African migrants living in Australia. Most participants experienced good mental health and positive feelings about the future, findings that differ from previous studies about African migrants. Future research could examine in more detail the experiences of voluntary migrants compared to involuntary migrants to inform targeted interventions to meet the potentially different needs of each group.

Further research could also investigate whether the well-being of involuntary migrants differs by gender because of different experiences of persecution, for example, torture and rape. Mental health nurses should continually update their knowledge about mental health services and resources available for migrants and ensure that all migrants can access these services if needed.

\section{References}

Abkhezr P, McMahon M, Glasheen Ket al (2018) Finding voice through narrative storytelling: an exploration of the career development of young African females with refugee backgrounds. Journa of Vocational Behavior. 105, 17-30.

Abur W (2018) Settlement Strategies for the South Sudanese Community in Melbourne: An Analysis of Employment and Sport Participation. vuir. vu.edu.au/36189/1/ABUR\%2C\%20William\%20 PhD\%20thesis\%20no\%20signature.pdf (Last accessed: 3 July 2019.)

Abur W, Spaaij R (2016) Settlement and employment experiences of South Sudanese people from refugee backgrounds in Melbourne, Australia. Australasian Review of African Studies. 37, 2, 107-128.

Australian Bureau of Statistics (2006) 2006 Census Community Profiles. quickstats. censusdata.abs.gov.au/census services/ getproduct/census/2006/communityprofile/0 (Last accessed: 3 July 2019.)

Australian Bureau of Statistics (2011) 2011 Census Community Profiles. quickstats.censusdata.abs. gov.au/census_services/getproduct/census/2011/ communityprofile/0 (Last accessed: 3 July 2019.)

Baird M (2012) Well-being in refugee women experiencing cultural transition. Advances in Nursing Science. 35, 3, 249-263

Beiser M, Hou F (2001) Language acquisition unemployment and depressive disorder among Southeast Asian refugees: a 10-year study. Social Science and Medicine. 53, 10, 1321-1334.

Berry J (1997) Immigration, acculturation, and adaptation. Applied Psychology. 46, 1, 5-34.

Bhugra D, Becker M (2005) Migration, cultura bereavement and cultural identity. World Psychiatry. 4, 1, 18-24.

Brand R, Lon J, Guilfoyle A (2014) Young African female refugees' sense of acculturation and community connection in Western Australia. Office Bearers of the APS College of Community Psychologists. 26, 2, 90-109.
Cassidy R (2004) Involuntary and Voluntary Migrant Estimates. copafs.org/UserFiles/file/seminars/ methodology_and_data_quality/Involuntary $\% 20$ and\%20Voluntary\%20Migarant\%20Estimates.pdf (Last accessed: 3 July 2019.)

Fryer D, Payne R (1986) Being unemployed: a review of the literature on the psychological experience of unemployment. International Review of Industrial and Organizational Psychology. 1,1,235-277.

Grinberg L, Grinberg R (1989) Psychoanalytic Perspectives on Migration and Exile. Yale University Press, New Haven CT

Guruge S, Hunter J, Barker K et al (2010) Immigrant women's experiences of receiving care in a mobile health clinic. Journal of Advanced Nursing. $66,2,350-359$.

Hack-Polay D (2012) When home isn't home - a study of homesickness and coping strategies among migrant workers and expatriates. International Journal of Psychological Studies. 4, 3,62-72.

Hack-Polay D, Mendy J (2018) And labor came to us: making use of an opportune workforce-enhancing migrant integration into British economy. Labor Studies Journal. 43, 1, 29-45.

Hancock P (2009) Recent African refugees to Australia: analysis of current refugee services, a case study from Western Australia. International Journal of Psychological Studies. 1, 2, 10-17.

Ingleby D (Ed) (2005) Forced Migration and Mental Health: Rethinking the Care of Refugees and Displaced Persons. Springer, New York NY.

International Organization for Migration (2015) World Migration Report 2015. publications. iom.int/system/files/wmr2015_en.pdf (Last accessed: 3 July 2019.)

Kuyini A, Kivunja C (2018) African refugee spouses' experience of resettlement in regional Australia: disempowering and empowering narratives. International Social Work. doi 10.1177/0020872818808352
Lindencrona F, Ekblad S, Hauff E (2008) Mental health of recently resettled refugees from the Middle East in Sweden: the impact of preresettlement trauma, resettlement stress and capacity to handle stress. Social Psychiatry and Psychiatric Epidemiology. 43, 2, 121-131.

Lustig S, Kia-Keating M, Knight W et al (2004) Review of child and adolescent refugee mental health. Journal of the American Academy of Child and Adolescent Psychiatry. 43, 1, 24-36.

Luthra R, Platt L, Salamonska J (2014) Migrant Diversity, Migration Motivations and Early Integration: The Case of Poles in Germany, the Netherlands, London and Dublin. Ise.ac.uk/ europeanInstitute/LEQS\%20Discussion\%20 Paper\%20Series/LEQSPaper74.pd (Last accessed: 3 July 2019.)

McMichael C, Gifford S, Correa-Velez I (2011) Negotiating family, navigating resettlement: family connectedness amongst resettled youth with refugee backgrounds living in Melbourne, Australia Journal of Youth Studies. 14, 2, 179-195.

Mendy J, Hack-Polay D (2018) Learning from failure: a study of failed enterprises of selfemployed African migrants in the UK. Journa of Small Business and Enterprise Development. 25, 2,330-343.

Murphy G, Athanasou J (1999) The effect of unemployment on mental health. Journal of Occupational and Organizational Psychology. 72, 1, 83-99.

Murray K (2010) Sudanese perspectives on resettlement in Australia. Journal of Pacific Rim Psychology. 4, 1, 30-43

Murray K, Davidson G, Schweitzer R (2010) Review of refugee mental health interventions following resettlement: best practices and recommendations. American Journal of Orthopsychiatry. 80, 4, 576-585

Ogunsiji 0, Wilkes L, Jackson D et al (2012) Beginning again: west African women's experiences. Journal of Transcultural Nursing. 23,3,279-286.
Paul K, Moser K (2009) Unemployment impairs mental health: meta-analyses. Journal of Vocational Behaviour. 74, 3, 264-282.

Pittaway E, Muli C, Shteir S (2009) 'I have voice - hear me!' Findings of an Australian study examining the resettlement and integration experience of refugees and migrants from the horn of Africa in Australia. Refuge. 26, 2, $133-146$.

Poppitt G, Frey R (2007) Sudanese adolescent refugees: acculturation and acculturative stress. Australian Journal of Guidance and Counselling. $17,2,160-181$.

Porter M, Haslam N (2005) Predisplacement and postdisplacement factors associated with mental health of refugees and internally displaced persons. Journal of the American Medical Association. 294, 5, 602-612.

Renzaho A, Vignjevic S (2011) The impact of a parenting intervention in Australia among migrants and refugees from Liberia, Sierra Leone, Congo, and Burundi. Journal of Family Studies. 17,1,71-79.

Savic M, Chur-Hansen A, Mahmood M et al (2013) Separation from family and its impact on the mental health of Sudanese refugees in Australia: a qualitative study. Australian and New Zealand Journal of Public Health. 37, 4, 383-388.

Schweitzer R, Melville F, Steel Z et al (2006) Trauma, post-migration living difficulties, and social support as predictors of psychological adjustment in resettled Sudanese refugees. Australian and New Zealand Journal of Psychiatry. 40, 2, 179-187.

United Nations (2015) International Migration Report 2015. un.org/en/development/ desa/population/migration/publications migrationreport/docs/MigrationReport2015 Highlights.pdf (Last accessed: 3 July 2019.)

Ward C (2000) Migration, Metamorphosis and the Residual Link: Resources of British Women to Re-invent Themselves. Unpublished PhD thesis. Murdoch University, Perth WA.

Winkelman M (1994) Cultural shock and adaptation. Journal of Counseling and Development. $73,2,121-126$. 